it could draw together such participants and many will feel that the Foundation is owed a debt of gratitude for publishing these deliberations.

M.W.

\section{THE MEDICAL ANNUAL}

Edited by Sir Henry Tidy, K.B.E., M.A., M.D., F.R.C.P., and R. Milnes Walker, M.S., F.R.C.S., with 47 contributors. Pp. xliv +548 , with 63 illustrations. Bristol: John Wright \& Sons Ltd. 1955. 32s. 6d.

This book is an annual abstract of important papers of general interest. Mohammed can no longer go to the mountain of medical literature, and this annual successfully brings a panoramic glimpse of the mountain to Mohammed. Its success is based upon expert editing and a galaxy of contributors of an eminence rarely found in abstracting services.

No doubt there are economic reasons for the unfortunate inclusion of drug-plugging advertisements, but even these include such intriguing matters as ' a culture for Candida.' Again, some hormones continue to be issued in blunderbuss combinations and, the medicinal compound of the ballad, are efficacious in every case.

The volume can be highly recommended to doctors in every branch of the profession. There can be few medical books with such a universal appeal.

I.L.E.

\section{MYSTERIOUS WATERS TO GUARD}

By Leslie Bourne, M.D., C.M., M.Sc., F.R.C.P., F.I.C.A., D.A., F.A.C.A., F.F.A.R.C.S. Pp. xvi + 398, illustrated. Oxford: Blackwell Scientific Publications. 1955. 42s.

Under this title is published a collection of addresses and essays by the distinguished Canadian Anaesthetist, Dr. Leslie Bourne, Emeritus Professor of Anaesthesia at McGill University, during the last 30 years.

Dr. Bourne deals with a wide variety of subjects in his addresses. There are two short historical reviews; accounts of recent advances given in the years 1934, 1948 and 1950; the choice of anaesthesia for tuberculous patients and for emergency surgery; and many other subjects. His style is clear and easily readable, but his tendency to commence his addresses with references to the great philosophers and the occasional inclusion of poetry seems pompous.

Among his essays are his impressions of the celebrations of the Centenary of Anaesthesia in London in 1946, which was printed in Anaesthesiology in 1948, and an essay entitled 'Breathing in Anesthesia ' which appeared as an editorial in the same journal in March 1942.

A criticism of the work is the inclusion of many chapters with much the same content. Subjects discussed with much frequency in the first half of the book are Metabolic Changes in Anaesthesia; Analgesia in Obstetrics; Analeptics; and Premedication for Relief of Pre-operative Fear, while descriptions of the three-year course in Anaesthesia at McGill University occur in at least three chapters in the latter half.

Photographs of many well-known anaesthetists and scientists from various parts of the world and professors at McGill University, and inexplicably of a late headmaster of the Lodge School, Barbados, are distributed through the book.

Full references are given at the end.

The printers have erred badly in the top line of page 146 , otherwise the book is well produced.

\section{BREAST CANCER AND ITS DIAGNOSIS AND TREATMENT}

By Edward F. Lewinson, B.S., M.D., F.A.C.S. Pp. 478. London: Baillière, Tindall and Cox. 1955. I 14 s.

This book is a comprehensive presentation of modern thought and knowledge regarding carcinoma of the breast. Every conceivable aspect of the subject is fully dealt with, the British and American literature is thoroughly reviewed; the illustrations are of high standard and, for the most part, the text is clear and logical.

As might perhaps be expected from a member of the surgical school founded by Halsted, the author is a staunch supporter of radical mastectomy. He appears to look to extended radical mastectomy forco future advances in treatment and has little use for the? conservative attitude towards operation which has become popular in recent years. It cannot be said that he produces convincing proof to support these views.

H.L.B.

\section{CORNEAL GRAFTS}

Edited by B. W. Rycroft, O.B.E., M.D., D.O.M.S., F.R.C.S. Pp. xii +285 . London: Butterworth \& Co. Ltd. I955. 57s. 6d.

This, the first text book on Corneal Grafting to be published in English, is a welcome and important addition to ophthalmic literature. The list of I 5 contributors from five countries (Britain, France, Spain, Switzerland and the United States) is an impressive one. It includes many of the leading authorities on the subject throughout the world. The result is a reliable and well-balanced account of every aspect of keratoplasty.

The first three chapters deal with the history of the operation, the anatomy and physiology of the cornea and the histo-pathology of corneal grafts. Apart from providing a useful introduction to the clinical side of the subject, they should be of value to everyone interested in tissue grafting. The main body of the book is devoted to the selection of cases, the operative details of lamellar and perforating 
grafts, the special instruments required, the postoperative treatment and complications and an assessment of the results. The collection and storage of whole eyes and corneas and the medicolegal problems involved are discussed. There is also a chapter on the associated use of contact lenses.

There are no major faults, but three minor ones may be mentioned. The historical survey would be better proportioned if less than seven pages were devoted to the early and unsuccessful stages of corneal grafting and more than two pages to this century, which saw the birth and development of the operation as a practical procedure. Secondly, although the post-operative use of cortisone is mentioned in several chapters, it is not discussed as fully as its importance would seem to warrant. Lastly, the section on the legal problems involved in collecting donor material is misleading, at any rate as far as this country is concerned. The position is, unfortunately, much more difficult and confused than is apparent from a reading of these pages. Ministry of Health regulations on the collecting of cadaveric eyes have modified the Corneal Grafting Act almost to the point of nullifying it.

But these, it must be repeated, are minor criticisms. On the other hand, it would be tedious to enumerate all the qualities of a work which can serve as a model for all text books of this kind. Special tribute should, however, be paid to the excellence of the translating and the uniformly lucid presentation which it ensures. The text is beautifully illustrated and well supported by a full bibliography and index.

Every ophthalmologist needs to know about corneal grafting, its possibilities and its limitations, even though the majority may never perform the operation. To them and to all other medical men or physiologists interested in the subject, this book is quite simply indispensable.

\section{J.J.T.}

\section{PSYCHOLOGICAL MEDICINE}

\section{A Short Introduction to Psychiatry}

By D. Curran, M.B., F.R.C.P., D.P.M. and M. Partridge, M.A., D.M., D.P.M. Fourth Edition. Pp. viii +407 , with 20 illustrations. Edinburgh: E. \& S. Livingstone Ltd. 1955. 2 Is.

'Curran and Guttman's '-well known to students over two decades, now appears with a new co-author to replace the late Dr. Eric Guttman. Post war progress in Psychiatry is reflected in this latest edition, which has doubled in size since the third edition appeared in 1949. There are some noticeable changes - the War Psychiatry Appendix has been excised, and the specialized forms of treatment now in general use have been explained in great detail. An interesting innovation is a chapter on 'Peripheral Psychiatry' that borderline of psychosomatics, enuretics, somnambulists, epi- leptics, and others who constitute problems which invade the whole field of medicine. For the rest, the mixture is as before, sumendus pro re nata!

\section{PERSONALITY CHANGES FOLLOWING FRONTAL LEUCOTOMY}

By' P. McDonald Tow, Ph.D., M.B., B.S., M.R.C.S. Pp. $x v+262$, with 27 illustrations. London: Geoffrey Cumberlege, Oxford University Press. 1955. 35s.

The general conclusions presented in this book are not new. They support and amplify the work of previous investigators into post-leucotomy effects -a topic which has aroused much interest and some controversy during the last decade. What is important in the work of Dr. Tow, however, is the evidence upon which his own conclusions are based, and, more particularly, his methodology. The latter, like Kant's Good Will, shines like a jewel in its own setting, preserving a sensible balance between psychological naiveté and the specialized electronic instrumentation used in similar studies. In this respect, too, the technique of assessment has an outstanding advantage-from the medical readers' point of view-over the classical works of Rylander and Halstead, an added advantage being the homogeneity of the sample. All members of the group received similar surgical treatment, and the pre- and post-operative investigations therefore possess a more homogenous neurological significance than the mixed bag of intracranial disorders usually included in such studies.

The work is rather more limited than the title suggests, in that it describes only the more intellectual aspects of the personality-vocabulary, abstractive thinking, fluency, persistence, speed and accuracy, etc.-and excludes the equally important emotional components, in which post-operative changes are greatest and usually the most favourable. This does not detract from the value of the work, however, which lies in the simplicity and exceptional detailing of every phase of the author's method, and the careful and thorough sifting of evidence. Because of this very lucid exposition, the book will appeal to a very much wider medical readership than any previous account. It includes an historical and inter-disciplinary survey of all work up to the present, a technical description of the operation, well illustrated with diagrams and radiographs, a careful and concise statement of the author's position with regard to statistical significance, and a full and very representative bibliography. The bulk of the volume is taken up with the dozen or so tests applied, each of which has a chapter to itself and indeed the text could be used as a manual for those interested in the objective assessment of human behaviour, irrespective of their speciality. The implications of this study are very much wider than the field of leucotomy itself, however, and it will prove an important stimulant to all who are actively concerned with problems of the cerebral basis of behaviour. 